\title{
Functional equations and inequalities in matrix paranormed spaces
}

\author{
Choonkil Park' , Jung Rye Lee² and Dong Yun Shin³
}

"Correspondence: dyshin@uos.ac.kr ${ }^{3}$ Department of Mathematics,

University of Seoul, Seoul, 130-743, Korea

Full list of author information is available at the end of the article

\begin{abstract}
In this paper, we prove the Hyers-Ulam stability of the Cauchy additive functional inequality, the Cauchy additive functional equation and the quadratic functional equation in matrix paranormed spaces.
\end{abstract}

MSC: Primary 47L25; 39B82; 39B72; 46L07; 39B52; 39B62

Keywords: Jordan-von Neumann functional equation; operator space; matrix paranormed space; Hyers-Ulam stability; functional equation; functional inequality

\section{Introduction and preliminaries}

The concept of statistical convergence for sequences of real numbers was introduced by Fast [1] and Steinhaus [2] independently, and since then several generalizations and applications of this notion have been investigated by various authors (see [3-7]). This notion was defined in normed spaces by Kolk [8].

We recall some basic facts concerning Fréchet spaces.

Definition 1.1 [9] Let $X$ be a vector space. A paranorm $P(\cdot): X \rightarrow[0, \infty)$ is a function on $X$ such that

(1) $P(0)=0$;

(2) $P(-x)=P(x)$;

(3) $P(x+y) \leq P(x)+P(y)$ (triangle inequality);

(4) If $\left\{t_{n}\right\}$ is a sequence of scalars with $t_{n} \rightarrow t$ and $\left\{x_{n}\right\} \subset X$ with $P\left(x_{n}-x\right) \rightarrow 0$, then $P\left(t_{n} x_{n}-t x\right) \rightarrow 0$ (continuity of multiplication).

The pair $(X, P(\cdot))$ is called a paranormed space if $P(\cdot)$ is a paranorm on $X$.

The paranorm is called total if, in addition, we have

(5) $P(x)=0$ implies $x=0$.

A Fréchet space is a total and complete paranormed space.

The stability problem of functional equations originated from the question of Ulam [10] concerning the stability of group homomorphisms.

The functional equation

$$
f(x+y)=f(x)+f(y)
$$

is called the Cauchy additive functional equation. In particular, every solution of the Cauchy additive functional equation is said to be an additive mapping. Hyers [11] gave the

\section{Springer}

(c)2013 Park et al.; licensee Springer. This is an Open Access article distributed under the terms of the Creative Commons Attribution License (http://creativecommons.org/licenses/by/2.0), which permits unrestricted use, distribution, and reproduction in any medium, provided the original work is properly cited. 
first affirmative partial answer to the question of Ulam for Banach spaces. Hyers' theorem was generalized by Aoki [12] for additive mappings and by Rassias [13] for linear mappings by considering an unbounded Cauchy difference. A generalization of the Rassias theorem was obtained by Găvruta [14] by replacing the unbounded Cauchy difference by a general control function in the spirit of Rassias' approach.

In 1990, during the 27th International Symposium on Functional Equations, Rassias [15] asked the question whether such a theorem can also be proved for $p \geq 1$. In 1991, Gajda [16], following the same approach as in Rassias [13], gave an affirmative solution to this question for $p>1$. It was shown by Gajda [16], as well as by Rassias and Šemrl [17], that one cannot prove a Rassias-type theorem when $p=1$ ( $c f$. the books of Czerwik [18] and Hyers et al. [19]).

The functional equation

$$
f(x+y)+f(x-y)=2 f(x)+2 f(y)
$$

is called a quadratic functional equation. In particular, every solution of the quadratic functional equation is said to be a quadratic mapping. A Hyers-Ulam stability problem for the quadratic functional equation was proved by Skof [20] for mappings $f: X \rightarrow Y$, where $X$ is a normed space and $Y$ is a Banach space. Cholewa [21] noticed that the theorem of Skof is still true if the relevant domain $X$ is replaced by an Abelian group. Czerwik [22] proved the Hyers-Ulam stability of the quadratic functional equation. The stability problems of several functional equations have been extensively investigated by a number of authors, and there are many interesting results concerning this problem (see [23-27]). In [28], Gilányi showed that if $f$ satisfies the functional inequality

$$
\left\|2 f(x)+2 f(y)-f\left(x y^{-1}\right)\right\| \leq\|f(x y)\|,
$$

then $f$ satisfies the Jordan-von Neumann functional equation

$$
2 f(x)+2 f(y)=f(x y)+f\left(x y^{-1}\right) .
$$

See also [29]. Gilányi [30] and Fechner [31] proved the Hyers-Ulam stability of functional inequality (1.1).

Park et al. [32] proved the Hyers-Ulam stability of the following functional inequality:

$$
\|f(x)+f(y)+f(z)\| \leq\|f(x+y+z)\| .
$$

The abstract characterization given for linear spaces of bounded Hilbert space operators in terms of matricially normed spaces [33] implies that quotients, mapping spaces and various tensor products of operator spaces may again be regarded as operator spaces. Owing in part to this result, the theory of operator spaces is having an increasingly significant effect on operator algebra theory (see [34]).

The proof given in [33] appealed to the theory of ordered operator spaces [35]. Effros and Ruan [36] showed that one can give a purely metric proof of this important theorem by using the technique of Pisier [37] and Haagerup [38] (as modified in [39]).

We will use the following notations:

$M_{n}(X)$ is the set of all $n \times n$-matrices in $X$; 
$e_{j} \in M_{1, n}(\mathbb{C})$ is that $j$ th component is 1 and the other components are zero;

$E_{i j} \in M_{n}(\mathbb{C})$ is that $(i, j)$-component is 1 and the other components are zero;

$E_{i j} \otimes x \in M_{n}(X)$ is that $(i, j)$-component is $x$ and the other components are zero.

For $x \in M_{n}(X), y \in M_{k}(X)$,

$$
x \oplus y=\left(\begin{array}{ll}
x & 0 \\
0 & y
\end{array}\right) .
$$

Note that $\left(X,\left\{\|\cdot\|_{n}\right\}\right)$ is a matrix normed space if and only if $\left(M_{n}(X),\|\cdot\|_{n}\right)$ is a normed space for each positive integer $n$ and $\|A x B\|_{k} \leq\|A\|\|B\|\|x\|_{n}$ holds for $A \in M_{k, n}, x=\left[x_{i j}\right] \in$ $M_{n}(X)$ and $B \in M_{n, k}$, and that $\left(X,\left\{\|\cdot\|_{n}\right\}\right)$ is a matrix Banach space if and only if $X$ is a Banach space and $\left(X,\left\{\|\cdot\|_{n}\right\}\right)$ is a matrix normed space.

Definition 1.2 Let $(X, P(\cdot))$ be a paranormed space.

(1) $\left(X,\left\{P_{n}(\cdot)\right\}\right)$ is a matrix paranormed space if $\left(M_{n}(X), P_{n}(\cdot)\right)$ is a paranormed space for each positive integer $n, P_{n}\left(E_{k l} \otimes x\right)=P(x)$ for $x \in X$, and $P\left(x_{k l}\right) \leq P_{n}\left(\left[x_{i j}\right]\right)$ for $\left[x_{i j}\right] \in M_{n}(X)$.

(2) $\left(X,\left\{P_{n}(\cdot)\right\}\right)$ is a matrix Fréchet space if $X$ is a Fréchet space and $\left(X,\left\{P_{n}(\cdot)\right\}\right)$ is a matrix paranormed space.

Let $E, F$ be vector spaces. For a given mapping $h: E \rightarrow F$ and a given positive integer $n$, define $h_{n}: M_{n}(E) \rightarrow M_{n}(F)$ by

$$
h_{n}\left(\left[x_{i j}\right]\right)=\left[h\left(x_{i j}\right)\right]
$$

for all $\left[x_{i j}\right] \in M_{n}(E)$.

In Section 2, we prove the Hyers-Ulam stability of Cauchy additive functional inequality (1.2) in matrix paranormed spaces. In Section 3, we prove the Hyers-Ulam stability of the Cauchy additive functional equation in matrix paranormed spaces. In Section 4, we prove the Hyers-Ulam stability of the quadratic functional equation in matrix paranormed spaces.

Throughout this paper, let $\left(X,\left\{\|\cdot\|_{n}\right\}\right)$ be a matrix Banach space and $\left(Y,\left\{P_{n}(\cdot)\right\}\right)$ be a matrix Fréchet space.

\section{Hyers-Ulam stability of additive functional inequality (1.2) in matrix paranormed spaces}

In this section, we prove the Hyers-Ulam stability of additive functional inequality (1.2) in matrix paranormed spaces.

Lemma 2.1 Let $\left(X,\left\{P_{n}(\cdot)\right\}\right)$ be a matrix paranormed space. Then

(1) $P\left(x_{k l}\right) \leq P_{n}\left(\left[x_{i j}\right]\right) \leq \sum_{i, j=1}^{n} P\left(x_{i j}\right)$ for $\left[x_{i j}\right] \in M_{n}(X)$;

(2) $\lim _{s \rightarrow \infty} x_{s}=x$ if and only if $\lim _{s \rightarrow \infty} x_{s i j}=x_{i j}$ for $x_{s}=\left[x_{s i j}\right], x=\left[x_{i j}\right] \in M_{k}(X)$.

Proof (1) By Definition 1.2, $P\left(x_{k l}\right) \leq P_{n}\left(\left[x_{i j}\right]\right)$.

Since $\left[x_{i j}\right]=\sum_{i, j=1}^{n} E_{i j} \otimes x_{i j}$,

$$
P_{n}\left(\left[x_{i j}\right]\right)=P_{n}\left(\sum_{i, j=1}^{n} E_{i j} \otimes x_{i j}\right) \leq \sum_{i, j=1}^{n} P_{n}\left(E_{i j} \otimes x_{i j}\right)=\sum_{i, j=1}^{n} P\left(x_{i j}\right) .
$$


(2) By (1), we have

$$
P\left(x_{s k l}-x_{k l}\right) \leq P_{n}\left(\left[x_{s i j}-x_{i j}\right]\right)=P_{n}\left(\left[x_{s i j}\right]-\left[x_{i j}\right]\right) \leq \sum_{i, j=1}^{n} P\left(x_{s i j}-x_{i j}\right) .
$$

So, we get the result.

Lemma 2.2 Let $\left(X,\left\{\|\cdot\|_{n}\right\}\right)$ be a matrix normed space. Then

(1) $\left\|E_{k l} \otimes x\right\|_{n}=\|x\|$ for $x \in X$;

(2) $\left\|x_{k l}\right\| \leq\left\|\left[x_{i j}\right]\right\|_{n} \leq \sum_{i, j=1}^{n}\left\|x_{i j}\right\|$ for $\left[x_{i j}\right] \in M_{n}(X)$;

(3) $\lim _{n \rightarrow \infty} x_{n}=x$ if and only if $\lim _{n \rightarrow \infty} x_{i j n}=x_{i j}$ for $x_{n}=\left[x_{i j n}\right], x=\left[x_{i j}\right] \in M_{k}(X)$.

Proof (1) Since $E_{k l} \otimes x=e_{k}^{*} x e_{l}$ and $\left\|e_{k}^{*}\right\|=\left\|e_{l}\right\|=1,\left\|E_{k l} \otimes x\right\|_{n} \leq\|x\|$. Since $e_{k}\left(E_{k l} \otimes x\right) e_{l}^{*}=x$, $\|x\| \leq\left\|E_{k l} \otimes x\right\|_{n}$. So, $\left\|E_{k l} \otimes x\right\|_{n}=\|x\|$.

(2) Since $e_{k} x e_{l}^{*}=x_{k l}$ and $\left\|e_{k}\right\|=\left\|e_{l}^{*}\right\|=1,\left\|x_{k l}\right\| \leq\left\|\left[x_{i j}\right]\right\|_{n}$. Since $\left[x_{i j}\right]=\sum_{i, j=1}^{n} E_{i j} \otimes x_{i j}$,

$$
\left\|\left[x_{i j}\right]\right\|_{n}=\left\|\sum_{i, j=1}^{n} E_{i j} \otimes x_{i j}\right\|_{n} \leq \sum_{i, j=1}^{n}\left\|E_{i j} \otimes x_{i j}\right\|_{n}=\sum_{i, j=1}^{n}\left\|x_{i j}\right\| .
$$

(3) By

$$
\left\|x_{k l n}-x_{k l}\right\| \leq\left\|\left[x_{i j n}-x_{i j}\right]\right\|_{n}=\left\|\left[x_{i j n}\right]-\left[x_{i j}\right]\right\|_{n} \leq \sum_{i, j=1}^{n}\left\|x_{i j n}-x_{i j}\right\|,
$$

we get the result.

We need the following result.

Lemma 2.3 Let $f: X \rightarrow Y$ be an odd mapping such that

$$
P(f(a)+f(b)+f(c)) \leq P(f(a+b+c))
$$

for all $a, b, c \in X$. Then $f: X \rightarrow Y$ is additive.

Proof Letting $c=-a-b$ in (2.1), we get $P(f(a)+f(b)+f(-a-b)) \leq P(f(0))=0$ for all $a, b \in X$. So,

$$
f(a)+f(b)-f(a+b)=f(a)+f(b)+f(-a-b)=0
$$

for all $a, b \in X$. Thus $f: X \rightarrow Y$ is additive.

Note that $P(2 x) \leq 2 P(x)$ for all $x \in Y$.

Theorem 2.4 Let $r, \theta$ be positive real numbers with $r>1$. Let $f: X \rightarrow Y$ be an odd mapping such that

$$
\begin{aligned}
P_{n}\left(f_{n}\left(\left[x_{i j}\right]\right)+f_{n}\left(\left[y_{i j}\right]\right)+f_{n}\left(\left[z_{i j}\right]\right)\right) \leq & P_{n}\left(f_{n}\left(\left[x_{i j}\right]+\left[y_{i j}\right]+\left[z_{i j}\right]\right)\right) \\
& +\sum_{i, j=1}^{n} \theta\left(\left\|x_{i j}\right\|^{r}+\left\|y_{i j}\right\|^{r}+\left\|z_{i j}\right\|^{r}\right)
\end{aligned}
$$


for all $x=\left[x_{i j}\right], y=\left[y_{i j}\right], z=\left[z_{i j}\right] \in M_{n}(X)$. Then there exists a unique additive mapping $A$ : $X \rightarrow Y$ such that

$$
P_{n}\left(f_{n}\left(\left[x_{i j}\right]\right)-A_{n}\left(\left[x_{i j}\right]\right)\right) \leq \sum_{i, j=1}^{n} \frac{2^{r}+2}{2^{r}-2} \theta\left\|x_{i j}\right\|^{r}
$$

for all $x=\left[x_{i j}\right] \in M_{n}(X)$.

Proof When $n=1,(2.2)$ is equivalent to

$$
P(f(a)+f(b)+f(c)) \leq P(f(a+b+c))+\theta\left(\|a\|^{r}+\|b\|^{r}+\|c\|^{r}\right)
$$

for all $a, b, c \in X$.

Letting $b=a$ and $c=-2 a$ in (2.4), we get

$$
P(f(2 a)-2 f(a)) \leq\left(2+2^{r}\right) \theta\|a\|^{r},
$$

and so

$$
P\left(f(a)-2 f\left(\frac{a}{2}\right)\right) \leq \frac{2+2^{r}}{2^{r}} \theta\|a\|^{r}
$$

for all $a, b \in X$.

One can easily show that

$$
P\left(2^{p} f\left(\frac{a}{2^{p}}\right)-2^{q} f\left(\frac{a}{2^{q}}\right)\right) \leq \sum_{l=p}^{q-1} \frac{\left(2+2^{r}\right) 2^{l}}{2^{(l+1) r}} \theta\|a\|^{r}
$$

for all $a, b \in X$ and nonnegative integers $p, q$ with $p<q$. It follows from (2.5) that the sequence $\left\{2^{l} f\left(\frac{a}{2^{l}}\right)\right\}$ is Cauchy for all $a \in X$. Since $Y$ is complete, the sequence $\left\{2^{l} f\left(\frac{a}{2^{l}}\right)\right\}$ converges. So, one can define the mapping $A: X \rightarrow Y$ by

$$
A(a)=\lim _{l \rightarrow \infty} 2^{l} f\left(\frac{a}{2^{l}}\right)
$$

for all $a \in X$.

Moreover, letting $p=0$ and passing the limit $q \rightarrow \infty$ in (2.5), we get

$$
P(f(a)-A(a)) \leq \frac{2^{r}+2}{2^{r}-2} \theta\|a\|^{r}
$$

for all $a \in X$.

It follows from (2.4) that

$$
\begin{aligned}
& P\left(2^{l}\left(f\left(\frac{a}{2^{l}}\right)+f\left(\frac{b}{2^{l}}\right)+f\left(\frac{c}{2^{l}}\right)\right)\right) \\
& \quad \leq 2^{l} P\left(f\left(\frac{a+b+c}{2^{l}}\right)\right)+\frac{2^{l}}{2^{l r}} \theta\left(\|a\|^{r}+\|b\|^{r}+\|c\|^{r}\right)
\end{aligned}
$$


for all $a, b, c \in X$. Passing the limit $l \rightarrow \infty$ in the above inequality, we get

$$
P(A(a)+A(b)+A(c)) \leq P(A(a+b+c))
$$

for all $a, b, c \in X$. Since $f: X \rightarrow Y$ is an odd mapping, the mapping $A: X \rightarrow Y$ is odd. By Lemma 2.3, $A: X \rightarrow Y$ is additive.

Now, let $T: X \rightarrow Y$ be another additive mapping satisfying (2.6). Then we have

$$
\begin{aligned}
P(A(a)-T(a)) & =P\left(2^{q} A\left(\frac{a}{2^{q}}\right)-2^{q} T\left(\frac{a}{2^{q}}\right)\right) \\
& \leq P\left(2^{q}\left(A\left(\frac{a}{2^{q}}\right)-g\left(\frac{a}{2^{q}}\right)\right)\right)+P\left(2^{q}\left(T\left(\frac{a}{2^{q}}\right)-g\left(\frac{a}{2^{q}}\right)\right)\right) \\
& \leq 2 \frac{2^{r}+2}{2^{r}-2} \frac{2^{q}}{2^{q r}} \theta\|a\|^{r},
\end{aligned}
$$

which tends to zero as $q \rightarrow \infty$ for all $a \in X$. So, we can conclude that $A(a)=T(a)$ for all $a \in X$. This proves the uniqueness of $A$.

By Lemma 2.1 and (2.6),

$$
P_{n}\left(f_{n}\left(\left[x_{i j}\right]\right)-A_{n}\left(\left[x_{i j}\right]\right)\right) \leq \sum_{i, j=1}^{n} P\left(f\left(x_{i j}\right)-A\left(x_{i j}\right)\right) \leq \sum_{i, j=1}^{n} \frac{\left(2+2^{r}\right)}{2^{r}-2} \theta\left\|x_{i j}\right\|^{r}
$$

for all $x=\left[x_{i j}\right] \in M_{n}(X)$. Thus $A: X \rightarrow Y$ is a unique additive mapping satisfying (2.3), as desired.

Theorem 2.5 Let $r, \theta$ be positive real numbers with $r<1$. Let $f: Y \rightarrow X$ be an odd mapping such that

$$
\begin{aligned}
\left\|f_{n}\left(\left[x_{i j}\right]\right)+f_{n}\left(\left[y_{i j}\right]\right)+f_{n}\left(\left[z_{i j}\right]\right)\right\|_{n} \leq & \left\|f_{n}\left(\left[x_{i j}\right]+\left[y_{i j}\right]+\left[z_{i j}\right]\right)\right\|_{n} \\
& +\sum_{i, j=1}^{n} \theta\left(P\left(x_{i j}\right)^{r}+P\left(y_{i j}\right)^{r}+P\left(z_{i j}\right)^{r}\right)
\end{aligned}
$$

for all $x=\left[x_{i j}\right], y=\left[y_{i j}\right], z=\left[z_{i j}\right] \in M_{n}(Y)$. Then there exists a unique additive mapping $A$ : $Y \rightarrow X$ such that

$$
\left\|f_{n}\left(\left[x_{i j}\right]\right)-A_{n}\left(\left[x_{i j}\right]\right)\right\|_{n} \leq \sum_{i, j=1}^{n} \frac{2+2^{r}}{2-2^{r}} \theta P\left(x_{i j}\right)^{r}
$$

for all $x=\left[x_{i j}\right] \in M_{n}(Y)$.

Proof Let $n=1$ in (2.7). Then (2.7) is equivalent to

$$
\|f(a)+f(b)+f(c)\| \leq\|f(a+b+c)\|+\theta\left(P(a)^{r}+P(b)^{r}+P(c)^{r}\right)
$$

for all $a, b, c \in Y$.

Letting $b=a$ and $c=-2 a$ in (2.9), we get

$$
\|f(2 a)-2 f(a)\| \leq\left(2+2^{r}\right) \theta P(a)^{r},
$$


and so

$$
\left\|f(a)-\frac{1}{2} f(2 a)\right\| \leq \frac{2+2^{r}}{2} \theta P(a)^{r}
$$

for all $a \in Y$.

One can easily show that

$$
\left\|\frac{1}{2^{p}} f\left(2^{p} a\right)-\frac{1}{2^{q}} f\left(2^{q} a\right)\right\| \leq \sum_{l=p}^{q-1} \frac{2^{l r}}{2^{l}} \frac{2+2^{r}}{2} \theta P(a)^{r}
$$

for all $a \in Y$ and nonnegative integers $p, q$ with $p<q$. It follows from (2.10) that the sequence $\left\{\frac{1}{2^{l}} f\left(2^{l} a\right)\right\}$ is Cauchy for all $a \in Y$. Since $X$ is complete, the sequence $\left\{\frac{1}{2^{2}} f\left(2^{l} a\right)\right\}$ converges. So, one can define the mapping $A: Y \rightarrow X$ by

$$
A(a)=\lim _{l \rightarrow \infty} \frac{1}{2^{l}} f\left(2^{l} a\right)
$$

for all $a \in Y$.

Moreover, letting $p=0$ and passing the limit $q \rightarrow \infty$ in (2.10), we get

$$
\|f(a)-A(a)\| \leq \frac{2+2^{r}}{2-2^{r}} \theta P(a)^{r}
$$

for all $a \in Y$.

It follows from (2.9) that

$$
\left\|\frac{1}{2^{l}}\left(f\left(2^{l} a\right)+f\left(2^{l} b\right)+f\left(2^{l} c\right)\right)\right\| \leq\left\|\frac{1}{2^{l}} f\left(2^{l}(a+b+c)\right)\right\|+\frac{2^{l r}}{2^{l}} \theta\left(\|a\|^{r}+\|b\|^{r}+\|c\|^{r}\right)
$$

for all $a, b, c \in Y$. Passing the limit $l \rightarrow \infty$ in the above inequality, we get

$$
\|A(a)+A(b)+A(c)\| \leq\|A(a+b+c)\|
$$

for all $a, b, c \in Y$. By [32, Lemma 3.1], the mapping $A: Y \rightarrow X$ is additive.

Now, let $T: Y \rightarrow X$ be another additive mapping satisfying (2.11). Let $n=1$. Then we have

$$
\begin{aligned}
\|A(a)-T(a)\| & =\left\|\frac{1}{2^{q}} A\left(2^{q} a\right)-\frac{1}{2^{q}} T\left(2^{q} a\right)\right\| \\
& \leq\left\|\frac{1}{2^{q}}\left(A\left(2^{q} a\right)-g\left(2^{q} a\right)\right)\right\|+\left\|\frac{1}{2^{q}}\left(T\left(2^{q} a\right)-g\left(2^{q} a\right)\right)\right\| \\
& \leq 2 \frac{2+2^{r}}{2-2^{r}} \frac{2^{q r}}{2^{q}} \theta P(a)^{r},
\end{aligned}
$$

which tends to zero as $q \rightarrow \infty$ for all $a \in Y$. So, we can conclude that $A(a)=T(a)$ for all $a \in Y$. This proves the uniqueness of $A$.

By Lemma 2.2 and (2.11),

$$
\left\|f_{n}\left(\left[x_{i j}\right]\right)-A_{n}\left(\left[x_{i j}\right]\right)\right\|_{n} \leq \sum_{i, j=1}^{n}\left\|f\left(x_{i j}\right)-A\left(x_{i j}\right)\right\| \leq \sum_{i, j=1}^{n} \frac{2+2^{r}}{2^{r}-2} \theta P\left(x_{i j}\right)^{r}
$$


for all $x=\left[x_{i j}\right] \in M_{n}(Y)$. Thus $A: Y \rightarrow X$ is a unique additive mapping satisfying (2.8), as desired.

\section{Hyers-Ulam stability of the Cauchy additive functional equation in matrix paranormed spaces}

In this section, we prove the Hyers-Ulam stability of the Cauchy additive functional equation in matrix paranormed spaces.

For a mapping $f: X \rightarrow Y$, define $D f: X^{2} \rightarrow Y$ and $D f_{n}: M_{n}\left(X^{2}\right) \rightarrow M_{n}(Y)$ by

$$
\begin{aligned}
& D f(a, b)=f(a+b)-f(a)-f(b), \\
& D f_{n}\left(\left[x_{i j}\right],\left[y_{i j}\right]\right):=f_{n}\left(\left[x_{i j}+y_{i j}\right]\right)-f_{n}\left(\left[x_{i j}\right]\right)-f_{n}\left(\left[y_{i j}\right]\right)
\end{aligned}
$$

for all $a, b \in X$ and all $x=\left[x_{i j}\right], y=\left[y_{i j}\right] \in M_{n}(X)$.

Theorem 3.1 Let $r, \theta$ be positive real numbers with $r>1$. Let $f: X \rightarrow Y$ be a mapping such that

$$
P_{n}\left(D f_{n}\left(\left[x_{i j}\right],\left[y_{i j}\right]\right)\right) \leq \sum_{i, j=1}^{n} \theta\left(\left\|x_{i j}\right\|^{r}+\left\|y_{i j}\right\|^{r}\right)
$$

for all $x=\left[x_{i j}\right], y=\left[y_{i j}\right] \in M_{n}(X)$. Then there exists a unique additive mapping $A: X \rightarrow Y$ such that

$$
P_{n}\left(f_{n}\left(\left[x_{i j}\right]\right)-A_{n}\left(\left[x_{i j}\right]\right)\right) \leq \sum_{i, j=1}^{n} \frac{2 \theta}{2^{r}-2}\left\|x_{i j}\right\|^{r}
$$

for all $x=\left[x_{i j}\right] \in M_{n}(X)$.

Proof Let $n=1$ in (3.1). Then (3.1) is equivalent to

$$
P(f(a+b)-f(a)-f(b)) \leq \theta\left(\|a\|^{r}+\|b\|^{r}\right)
$$

for all $a, b \in X$.

Letting $b=a$ in (3.3), we get

$$
P(f(2 a)-2 f(a)) \leq 2 \theta\|a\|^{r}
$$

and so

$$
P\left(f(a)-2 f\left(\frac{a}{2}\right)\right) \leq \frac{2}{2^{r}} \theta\|a\|^{r}
$$

for all $a, b \in X$.

One can easily show that

$$
P\left(2^{p} f\left(\frac{a}{2^{p}}\right)-2^{q} f\left(\frac{a}{2^{q}}\right)\right) \leq \sum_{l=p}^{q-1} \frac{2 \cdot 2^{l}}{2^{(l+1) r}} \theta\|a\|^{r}
$$


for all $a, b \in X$ and nonnegative integers $p, q$ with $p<q$. It follows from (3.4) that the sequence $\left\{2^{l} f\left(\frac{a}{2^{l}}\right)\right\}$ is Cauchy for all $a \in X$. Since $Y$ is complete, the sequence $\left\{2^{l} f\left(\frac{a}{2^{l}}\right)\right\}$ converges. So, one can define the mapping $A: X \rightarrow Y$ by

$$
A(a)=\lim _{l \rightarrow \infty} 2^{l} f\left(\frac{a}{2^{l}}\right)
$$

for all $a \in X$.

Moreover, letting $p=0$ and passing the limit $q \rightarrow \infty$ in (3.4), we get

$$
P(f(a)-A(a)) \leq \frac{2 \theta}{2^{r}-2}\|a\|^{r}
$$

for all $a \in X$.

It follows from (3.3) that

$$
\begin{aligned}
P\left(2^{l}\left(f\left(\frac{a+b}{2^{l}}\right)-f\left(\frac{a}{2^{l}}\right)-f\left(\frac{b}{2^{l}}\right)\right)\right) & \leq 2^{l} P\left(f\left(\frac{a+b}{2^{l}}\right)-f\left(\frac{a}{2^{l}}\right)-f\left(\frac{b}{2^{l}}\right)\right) \\
& \leq \frac{2^{l}}{2^{l r}} \theta\left(\|a\|^{r}+\|b\|^{r}\right),
\end{aligned}
$$

which tends to zero as $l \rightarrow \infty$. So, $P(A(a+b)-A(a)-A(b))=0$, i.e., $A(a+b)=A(a)+A(b)$ for all $a, b \in X$. Hence $A: X \rightarrow Y$ is additive.

The proof of the uniqueness of $A$ is similar to the proof of Theorem 2.4.

By Lemma 2.1 and (3.5),

$$
P_{n}\left(f_{n}\left(\left[x_{i j}\right]\right)-A_{n}\left(\left[x_{i j}\right]\right)\right) \leq \sum_{i, j=1}^{n} P\left(f\left(x_{i j}\right)-A\left(x_{i j}\right)\right) \leq \sum_{i, j=1}^{n} \frac{2 \theta}{2^{r}-2}\left\|x_{i j}\right\|^{r}
$$

for all $x=\left[x_{i j}\right] \in M_{n}(X)$. Thus $A: X \rightarrow Y$ is a unique additive mapping satisfying (3.2), as desired.

Theorem 3.2 Let $r, \theta$ be positive real numbers with $r<1$. Let $f: Y \rightarrow X$ be a mapping such that

$$
\left\|D f_{n}\left(\left[x_{i j}\right],\left[y_{i j}\right]\right)\right\|_{n} \leq \sum_{i, j=1}^{n} \theta\left(P\left(x_{i j}\right)^{r}+P\left(y_{i j}\right)^{r}\right)
$$

for all $x=\left[x_{i j}\right], y=\left[y_{i j}\right] \in M_{n}(Y)$. Then there exists a unique additive mapping $A: Y \rightarrow X$ such that

$$
\left\|f_{n}\left(\left[x_{i j}\right]\right)-A_{n}\left(\left[x_{i j}\right]\right)\right\|_{n} \leq \sum_{i, j=1}^{n} \frac{2 \theta}{2-2^{r}} P\left(x_{i j}\right)^{r}
$$

for all $x=\left[x_{i j}\right] \in M_{n}(Y)$.

Proof Let $n=1$ in (3.6). Then (3.6) is equivalent to

$$
\|f(a+b)-f(a)-f(b)\| \leq \theta\left(P(a)^{r}+P(b)^{r}\right)
$$

for all $a, b \in Y$. 
Letting $b=a$ in (3.8), we get

$$
\|f(2 a)-2 f(a)\| \leq 2 \theta P(a)^{r}
$$

and so

$$
\left\|f(a)-\frac{1}{2} f(2 a)\right\| \leq \theta P(a)^{r}
$$

for all $a \in Y$.

One can easily show that

$$
\left\|\frac{1}{2^{p}} f\left(2^{p} a\right)-\frac{1}{2^{q}} f\left(2^{q} a\right)\right\| \leq \sum_{l=p}^{q-1} \frac{2^{l r}}{2^{l}} \theta P(a)^{r}
$$

for all $a \in Y$ and nonnegative integers $p, q$ with $p<q$. It follows from (3.9) that the sequence $\left\{\frac{1}{2^{l}} f\left(2^{l} a\right)\right\}$ is Cauchy for all $a \in Y$. Since $X$ is complete, the sequence $\left\{\frac{1}{2^{l}} f\left(2^{l} a\right)\right\}$ converges. So, one can define the mapping $A: Y \rightarrow X$ by

$$
A(a)=\lim _{l \rightarrow \infty} \frac{1}{2^{l}} f\left(2^{l} a\right)
$$

for all $a \in Y$.

Moreover, letting $p=0$ and passing the limit $q \rightarrow \infty$ in (3.9), we get

$$
\|f(a)-A(a)\| \leq \frac{2 \theta}{2-2^{r}} P(a)^{r}
$$

for all $a \in Y$.

It follows from (3.8) that

$$
\left\|\frac{1}{2^{l}}\left(f\left(2^{l}(a+b)\right)-f\left(2^{l} a\right)-f\left(2^{l} b\right)\right)\right\| \leq \frac{2^{l r}}{2^{l}} \theta\left(\|a\|^{r}+\|b\|^{r}\right),
$$

which tends to zero as $l \rightarrow \infty$. So, $\|A(a+b)-A(a)-A(b)\|=0$, i.e., $A(a+b)=A(a)+A(b)$ for all $a, b \in Y$. Hence $A: Y \rightarrow X$ is additive.

The proof of the uniqueness of $A$ is similar to the proof of Theorem 2.5.

By Lemma 2.2 and (3.10),

$$
\left\|f_{n}\left(\left[x_{i j}\right]\right)-A_{n}\left(\left[x_{i j}\right]\right)\right\|_{n} \leq \sum_{i, j=1}^{n}\left\|f\left(x_{i j}\right)-A\left(x_{i j}\right)\right\| \leq \sum_{i, j=1}^{n} \frac{2 \theta}{2^{r}-2} P\left(x_{i j}\right)^{r}
$$

for all $x=\left[x_{i j}\right] \in M_{n}(Y)$. Thus $A: Y \rightarrow X$ is a unique additive mapping satisfying (3.7), as desired.

\section{Hyers-Ulam stability of the quadratic functional equation in matrix paranormed spaces}

In this section, we prove the Hyers-Ulam stability of the quadratic functional equation in matrix paranormed spaces. 
For a mapping $f: X \rightarrow Y$, define $D f: X^{2} \rightarrow Y$ and $D f_{n}: M_{n}\left(X^{2}\right) \rightarrow M_{n}(Y)$ by

$$
\begin{aligned}
& D f(a, b)=f(a+b)+f(a-b)-2 f(a)-2 f(b), \\
& D f_{n}\left(\left[x_{i j}\right],\left[y_{i j}\right]\right):=f_{n}\left(\left[x_{i j}+y_{i j}\right]\right)+f_{n}\left(\left[x_{i j}-y_{i j}\right]\right)-2 f_{n}\left(\left[x_{i j}\right]\right)-2 f_{n}\left(\left[y_{i j}\right]\right)
\end{aligned}
$$

for all $a, b \in X$ and all $x=\left[x_{i j}\right], y=\left[y_{i j}\right] \in M_{n}(X)$.

Theorem 4.1 Let $r, \theta$ be positive real numbers with $r>2$. Let $f: X \rightarrow Y$ be a mapping such that

$$
P_{n}\left(D f_{n}\left(\left[x_{i j}\right],\left[y_{i j}\right]\right)\right) \leq \sum_{i, j=1}^{n} \theta\left(\left\|x_{i j}\right\|^{r}+\left\|y_{i j}\right\|^{r}\right)
$$

for all $x=\left[x_{i j}\right], y=\left[y_{i j}\right] \in M_{n}(X)$. Then there exists a unique quadratic mapping $Q: X \rightarrow Y$ such that

$$
P_{n}\left(f_{n}\left(\left[x_{i j}\right]\right)-Q_{n}\left(\left[x_{i j}\right]\right)\right) \leq \sum_{i, j=1}^{n} \frac{2 \theta}{2^{r}-4}\left\|x_{i j}\right\|^{r}
$$

for all $x=\left[x_{i j}\right] \in M_{n}(X)$.

Proof Let $n=1$ in (4.1). Then (4.1) is equivalent to

$$
P(f(a+b)+f(a-b)-2 f(a)-2 f(b)) \leq \theta\left(\|a\|^{r}+\|b\|^{r}\right)
$$

for all $a, b \in X$.

Letting $a=b=0$ in (4.2), we get $P(2 f(0)) \leq 0$ and so $f(0)=0$.

Letting $b=a$ in (4.2), we get

$$
P(f(2 a)-4 f(a)) \leq 2 \theta\|a\|^{r},
$$

and so

$$
P\left(f(a)-4 f\left(\frac{a}{2}\right)\right) \leq \frac{2}{2^{r}} \theta\|a\|^{r}
$$

for all $a, b \in X$.

The rest of the proof is similar to the proof of Theorem 3.1.

Theorem 4.2 Let $r, \theta$ be positive real numbers with $r<2$. Let $f: Y \rightarrow X$ be a mapping such that

$$
\left\|D f_{n}\left(\left[x_{i j}\right],\left[y_{i j}\right]\right)\right\|_{n} \leq \sum_{i, j=1}^{n} \theta\left(P\left(x_{i j}\right)^{r}+P\left(y_{i j}\right)^{r}\right)
$$

for all $x=\left[x_{i j}\right], y=\left[y_{i j}\right] \in M_{n}(Y)$. Then there exists a unique quadratic mapping $Q: Y \rightarrow X$ such that

$$
\left\|f_{n}\left(\left[x_{i j}\right]\right)-Q_{n}\left(\left[x_{i j}\right]\right)\right\|_{n} \leq \sum_{i, j=1}^{n} \frac{2 \theta}{4-2^{r}} P\left(x_{i j}\right)^{r}
$$

for all $x=\left[x_{i j}\right] \in M_{n}(Y)$. 
Proof Let $n=1$ in (4.3). Then (4.3) is equivalent to

$$
\|f(a+b)+f(a-b)-2 f(a)-2 f(b)\| \leq \theta\left(P(a)^{r}+P(b)^{r}\right)
$$

for all $a, b \in Y$.

Letting $a=b=0$ in (4.4), we get $\|2 f(0)\| \leq 0$ and so $f(0)=0$.

Letting $b=a$ in (4.4), we get

$$
\|f(2 a)-4 f(a)\| \leq 2 \theta P(a)^{r}
$$

and so

$$
\left\|f(a)-\frac{1}{4} f(2 a)\right\| \leq \frac{\theta}{2} P(a)^{r}
$$

for all $a, b \in Y$.

The rest of the proof is similar to the proof of Theorem 3.2.

\section{Competing interests}

The authors declare that they have no competing interests.

\section{Authors' contributions}

All authors conceived of the study, participated in its design and coordination, drafted the manuscript, participated in the sequence alignment, and read and approved the final manuscript.

\section{Author details}

'Department of Mathematics, Research Institute for Natural Sciences, Hanyang University, Seoul, 133-791, Korea.

2Department of Mathematics, Daejin University, Pocheon, Kyeonggi 487-711, Korea. ${ }^{3}$ Department of Mathematics,

University of Seoul, Seoul, 130-743, Korea.

\section{Acknowledgements}

CP was supported by the Basic Science Research Program through the National Research Foundation of Korea funded by the Ministry of Education, Science and Technology (NRF-2012R1A1A2004299), and DYS was supported by the Basic Science Research Program through the National Research Foundation of Korea funded by the Ministry of Education, Science and Technology (NRF-2010-0021792)

Received: 8 February 2013 Accepted: 12 September 2013 Published: 19 Nov 2013

\section{References}

1. Fast, H: Sur la convergence statistique. Colloq. Math. 2, 241-244 (1951)

2. Steinhaus, H: Sur la convergence ordinaire et la convergence asymptotique. Colloq. Math. 2, 73-74 (1951)

3. Fridy, JA: On statistical convergence. Analysis 5, 301-313 (1985)

4. Karakus, S: Statistical convergence on probabilistic normed spaces. Math. Commun. 12, 11-23 (2007)

5. Mursaleen, M: $\lambda$-Statistical convergence. Math. Slovaca 50, 111-115 (2000)

6. Mursaleen, M, Mohiuddine, SA: On lacunary statistical convergence with respect to the intuitionistic fuzzy normed space. J. Comput. Appl. Math. 233, 142-149 (2009)

7. Šalát, T: On the statistically convergent sequences of real numbers. Math. Slovaca 30, 139-150 (1980)

8. Kolk, E: The statistical convergence in Banach spaces. Tartu Ülik. Toim. 928, 41-52 (1991)

9. Wilansky, A: Modern Methods in Topological Vector Space. McGraw-Hill, New York (1978)

10. Ulam, SM: A Collection of the Mathematical Problems. Interscience, New York (1960)

11. Hyers, DH: On the stability of the linear functional equation. Proc. Natl. Acad. Sci. USA 27, $222-224$ (1941)

12. Aoki, T: On the stability of the linear transformation in Banach spaces. J. Math. Soc. Jpn. 2, 64-66 (1950)

13. Rassias, TM: On the stability of the linear mapping in Banach spaces. Proc. Am. Math. Soc. 72, 297-300 (1978)

14. Găvruta, G: A generalization of the Hyers-Ulam-Rassias stability of approximately additive mappings. J. Math. Anal. Appl. 184, 431-436 (1994)

15. Rassias, TM: Problem 16; 2. Report of the 27 th international symp. on functional equations. Aequ. Math. 39, 292-293 309 (1990)

16. Gajda, Z: On stability of additive mappings. Int. J. Math. Math. Sci. 14, 431-434 (1991)

17. Rassias, TM, Šemrl, P: On the behaviour of mappings which do not satisfy Hyers-Ulam stability. Proc. Am. Math. Soc. $114,989-993(1992)$

18. Czerwik, P: Functional Equations and Inequalities in Several Variables. World Scientific, Singapore (2002) 
19. Hyers, DH, Isac, G, Rassias, TM: Stability of Functional Equations in Several Variables. Birkhäuser, Basel (1998)

20. Skof, F: Proprieta' locali e approssimazione di operatori. Rend. Semin. Mat. Fis. Milano 53, 113-129 (1983)

21. Cholewa, PW: Remarks on the stability of functional equations. Aequ. Math. 27, 76-86 (1984)

22. Czerwik, S: On the stability of the quadratic mapping in normed spaces. Abh. Math. Semin. Univ. Hamb. 62, 59-64 (1992)

23. Aczel, J, Dhombres, J: Functional Equations in Several Variables. Cambridge University Press, Cambridge (1989)

24. Eshaghi Gordji, M, Savadkouhi, MB: Stability of a mixed type cubic-quartic functional equation in non-Archimedean spaces. Appl. Math. Lett. 23, 1198-1202 (2010)

25. Isac, G, Rassias, TM: On the Hyers-Ulam stability of $\psi$-additive mappings. J. Approx. Theory 72, 131-137 (1993)

26. Jun, K, Lee, Y: A generalization of the Hyers-Ulam-Rassias stability of the Pexiderized quadratic equations. J. Math. Anal. Appl. 297, 70-86 (2004)

27. Park, C: Homomorphisms between Poisson JC*-algebras. Bull. Braz. Math. Soc. 36, 79-97 (2005)

28. Gilányi, A: Eine zur Parallelogrammgleichung äquivalente Ungleichung. Aequ. Math. 62, 303-309 (2001)

29. Rätz, J: On inequalities associated with the Jordan-von Neumann functional equation. Aequ. Math. 66, 191-200 (2003)

30. Gilányi, A: On a problem by K. Nikodem. Math. Inequal. Appl. 5, 707-710 (2002)

31. Fechner, W: Stability of a functional inequalities associated with the Jordan-von Neumann functional equation. Aequ. Math. 71, 149-161 (2006)

32. Park, C, Cho, Y, Han, M: Functional inequalities associated with Jordan-von Neumann-type additive functional equations. J. Inequal. Appl. 2007, Article ID 41820 (2007)

33. Ruan, ZJ: Subspaces of $C^{*}$-algebras. J. Funct. Anal. 76, 217-230 (1988)

34. Effros, E, Ruan, ZJ: On approximation properties for operator spaces. Int. J. Math. 1, 163-187 (1990)

35. Choi, MD, Effros, E: Injectivity and operator spaces. J. Funct. Anal. 24, 156-209 (1977)

36. Effros, E, Ruan, ZJ: On the abstract characterization of operator spaces. Proc. Am. Math. Soc. 119, $579-584$ (1993)

37. Pisier, G: Grothendieck's theorem for non-commutative $C^{*}$-algebras with an appendix on Grothendieck's constants. J. Funct. Anal. 29, 397-415 (1978)

38. Haagerup, U: Decomp. of completely bounded maps. Unpublished manuscript

39. Effros, E: On multilinear completely bounded module maps. In: Operator Algebras and Mathematical Physics. Contemp. Math., vol. 62, pp. 479-501. Am. Math. Soc., Providence (1987)

10.1186/1029-242X-2013-547

Cite this article as: Park et al.: Functional equations and inequalities in matrix paranormed spaces. Journal of Inequalities and Applications 2013, 2013:547

\section{Submit your manuscript to a SpringerOpen ${ }^{\ominus}$ journal and benefit from:}

- Convenient online submission

Rigorous peer review

- Immediate publication on acceptance

- Open access: articles freely available online

- High visibility within the field

- Retaining the copyright to your article 